\title{
HOW DOES ECONOMIC POLICY UNCERTAINTY AFFECT PRICES OF HOUSING? EVIDENCE FROM GERMANY
}

We test the interaction between housing prices and economic policy uncertainty with controlling for the effect of the interest rate in Germany. A bootstrap rolling-window Granger causality test method is utilized for the purpose of detecting their dynamic relationship, since we find significant structural changes across the full-sample of the time series which should be taken into account to avoid estimation errors, and more importantly to get a more instructive conclusion. We find that even in Germany, where house prices are famous for their stability, a strong bilateral Granger causality still exists after controlling for the interest rate of housing loans. Furthermore, we find that though the impact of economic policy uncertainty on housing prices could be positive or negative, it significantly reduces house price volatility, while house price volatility significantly raises economic policy uncertainty, which suggests that the frequently mentioned volatility spillover effect of uncertainty on the housing market is not explanatory. Our results indicate that when the subject is a pillar industry in the national economy, considering only the volatility spillover effect caused by economic policy uncertainty may be one-sided, and the purpose of policy change may be more worthy of consideration.

Keywords: economic policy uncertainty; house prices; rolling window; bootstrap; Granger causality

JEL Classifications: C32, G12, G18

DOI: $10.15611 /$ aoe.2019.1.06

\section{INTRODUCTION}

The interaction between economic policy uncertainty and asset prices has attracted a lot of attention in past decades, since cyclical economic fluctuations (or even crises) are often accompanied by larger fluctuations in macroeconomic variables (such as house prices), but also lead to greater uncertainty in the relevant economic policies. It seems natural to link the increase in house prices (or their volatility) to the increase in policy uncertainty because the government always likes to stabilize house prices

\footnotetext{
* School of Economics, Qingdao University, Ningxia Rd., Qingdao, Shandong, China.

** Antai College of Economics and Management, Shanghai Jiao Tong University, China.

*** Qingdao Municipal Center for Disease Control \& Prevention.
} 
(Simo-Kengne et al., 2013). This means that house prices may guide government's behavior to increasing the uncertainty of their economic policy . On the other hand, uncertainty shocks are claimed to have played an important role in driving global house price fluctuations (Hirata et al., 2012). However, whether economic policy uncertainty, as one of the uncertainties, will lead to greater fluctuations in house prices does not seem particularly clear. The reason is that despite the seemingly contagious nature of uncertainty itself (Bernanke, 1983; Rodrik, 1991; Aizenman and Marion, 1993; Baker et al., 2012; Brogaard and Detzel, 2015), governments are usually keen to stabilize house prices, and even if intensive economic policies are introduced, they may be designed to regulate them. Thus, though the most recent theoretical model proposed by Pastor and Veronesi (2011) demonstrates that political uncertainty increases the equity premium, which may result in higher costs of financing real estate projects, we are still confused about the impact of economic policy uncertainty on house prices since they only take into account the uncertainty itself, but ignore the directivity of these policies. In fact, the impact of policy uncertainty on asset prices may have other transmission mechanisms. For instance, Gilchrist et al. (2011) find that the impact of policy uncertainty on house prices may also channel through the balance sheet effect, as uncertainty increases the risk of default which further improves the transmission mechanism from the policy uncertainty to the market.

This question is even more interesting for Germany, which is known for its stable house prices worldwide, even during the 2008 financial crisis. In contrast to several countries where the real price of housing is increasing, in Germany it decreased at an average rate of approximately 1\% per year from 1997 to 2014. Although house prices tend to rise in the U.S., the U.K. and Japan, they remain stable in Germany due to the sound market mechanism and credit system, as well as a rational long-term policy orientation (Voigtländer; 2009, 2014). The impact of the real estate market on the development of the economy is much more notable after the outbreak of the subprime mortgage crisis (Demyanyk and Van Hemert, 2011). The global financial crisis has had a rather adverse impact on the economy of the major advanced countries, and Germany has experienced the most serious economic recession since 1949. However, the German economy recovered relatively quickly compared to other advanced countries. In general, economic policy uncertainty in Germany is relatively unchanged, while other countries show a clear upward trend and remain at a high level after the global financial crisis. Specifically, Germany's economy maintained stability during the raging European sovereign debt crisis and the bleak economic prospects. The stabilization in the real estate market has played a significant role 
in Germany's economic recovery (Voigtländer, 2014). In such a stable economic system, if the role of policy uncertainty is still significant, it will help to illustrate the important role of policy uncertainty in the real estate market.

Recent studies have examined the relationship between the real estate market and policy uncertainty. Aoki et al. (2004) argue that the effect of a structural change in the credit markets would decrease the effect of monetary policy on house prices and housing investment. Aye et al. (2012) show that a deficit spending shock has no impact on house prices. A deficit-financed tax cut shock persistently increases house prices, while a balanced budget shock permanently decreases them. However, the monetary policy and deficit spending shock cannot reflect all the effects from EPU onto the real estate market. Sum and Brown (2012) examine the effect of EPU on the performance of the real estate sector and find no significant causal link between EPU and the real estate sector. Ajmi et al. (2014) discover a twoway transmission channel between Real Estate Investment Trusts (REIT) conditional volatility and macroeconomic uncertainty and find no significant link between them. However, their results may be inaccurate due to the structural changes caused by huge economic fluctuations. El-Montasser et al. (2013) find the high uncertainty related to future economic fundamentals and policies increases house price volatility. Unfortunately, structural changes may cause the results to be unreliable, and the results from them cannot show specifically the positive or negative impacts.

Previous studies mostly test the link between real estate and the monetary policy in Germany; however, monetary policy cannot completely contain the policy changes. Iacoviello (2000) investigates the links between real estate and external shocks such as monetary shocks and demand shocks, and find that these shocks drive most of the short-term house price volatility in Germany. Although structural changes can be taken into account by using the structural vector autoregression (SVAR), he does not demonstrate if the impact is positive or negative. Calza et al. (2013) investigate housing finance and monetary transmission in Germany, and find that residential investment and house prices are usually more responsive to policy shocks when the mortgage market is flexible; dynamic links between policy shocks and house prices can be tested with the method of the two-sector dynamic stochastic general equilibrium model (DSGE model). These studies mostly focus on the real estate in Germany from the perspective of monetary policy and housing finance. El-Montasser et al. (2013) find a unidirectional causality running from policy uncertainty to real house prices in Germany; however, without considering the structural changes, their results may not be accurate (Balcilar 
et al., 2013) due to the impact of exogenous economic variables such as the financial crisis. Furthermore, these studies cannot identify whether the impact of policy uncertainty is positive or negative.

Unlike the previous literature, this investigation utilizes the economic policy uncertainty index proposed by Baker et al. (2016) to test its relationship with house prices in Germany. One of the contributions compared to previous research is that we take into account the fact that macroeconomics is constantly undergoing a series of structural changes. These structural changes include both long-term gradual change and short-term change, which make the time series analysis method based on the whole sample inefficient and even leads to estimation errors (Lee and Strazicich, 2004; Enders and Lee, 2012a; Enders and Lee, 2012b; Enders and Jones, 2016). We implement our investigation in the framework of a VAR model, taking into account both economic policy uncertainty and house prices, and controlling for the interest rate of housing loans. One of the main consequences of structural changes is that the parameters should be time-varying, therefore we implement a series of short and long-term parameter stability tests to investigate the stability of parameters in the full-sample VAR system. The results strongly suggest that structural changes should be taken into account both in the short and long run. Based on this, after using the Granger bootstrap full-sample causality test, we revisit the dynamic Granger causality between house prices and economic policy uncertainty by using the rolling-window based method proposed by Balcilar et al. (2013). We find a strong bilateral but time-varying relationship across the full sample, which suggests that economic policy uncertainty plays an important role in the real estate market in Germany. Evidence from the coefficients of the VAR models suggest that in most cases, economic policy uncertainty would lead to rises in the price of housing. To some extent this confirms our conjecture that the government always wants to take measures to keep house prices growing steadily, because it is an important part of a country's economic growth. To further prove this, we use the GARCH model based on $t$-distribution to measure the volatility of housing investment return, and test its interaction with the economic policy uncertainty using the rolling window approach. We expect the economic policy uncertainty to reduce housing market volatility if policy changes mainly aim at stabilizing house prices, and we expect the fluctuation of house prices should increase economic policy uncertainty if the real estate market is important enough for the economy in Germany. The result proves our conjecture but shows complex time-varying properties, which suggests that the impact of economic policy uncertainty is more significant after 2016, when house prices in Germany 
began to rise rapidly. Like previous studies, our research also shows the importance of economic policy uncertainty for the real estate market, but our research shows the difference with previous works. We find that economic policy uncertainty not only causes a risk premium just like other kinds of uncertainties, but it may also reduce asset price volatilities through constantly changing economic policies.

The rest of this paper is structured as follows: Section 2 introduces the theoretical model proposed by Pastor and Veronesi (2010, 2013). Section 3 explains the bootstrap rolling-window method. Section 4 describes the corresponding data and provides the empirical results and policy implications. Section 5 concludes the study.

\section{A GENERAL EQUILIBRIUM MODEL}

We reference the model from Pastor and Veronesi $(2010,2013)$ to explain how economic policy uncertainty affects the housing market from the "uncertainty" point of view. Pastor and Veronesi $(2010,2013)$ develop a general equilibrium model to explain the relationship between policy uncertainty and stock returns. Suppose a real estate market where the investors (denoted by $m$ ) are continuous with $m \in[0, T]$ in the limited time interval of $[0, T]$. The capital of investor $m$ at time $t$ is $B_{t}^{m}$. All investors' capital is equivalent to 1 at the beginning. The capital of investor $m$ is invested in a linear technology where the rate of return $H R_{t}^{m}$ is random. All profits from investing in real estate will be reinvested. In this case, the capital of investor $m$ changes as $d B_{t}^{m}=B_{t}^{m} d H R_{t}^{m}$. A continuous differential equation is constructed to describe the relationship between $d H R_{t}^{m}$ and the average coefficient of variation of economic policy gains for investors' profitability $\left(g_{t}\right)$ :

$$
d H R_{t}^{m}=\left(\mu_{1}+g_{t}\right) d t+\sigma d Z_{t}+\sigma_{1} d Z_{t}^{m},
$$

where $\left(\mu_{1}, \sigma, \sigma_{1}\right)$ are constants and can be observed. $\mu_{1}$ denotes other factors that affect $H R_{t}^{m}, \sigma$ and $\sigma_{1}$ are coefficients. $Z_{t}$ is a Brownian motion of the system and $Z_{t}^{m}$ is an independent Brownian motion of investor $m$. 
The impact of economic policy $g_{t}$ will not change until a new policy is implemented at a given time $\tau$ for $\tau \in(0, T)$. At time $\tau$, the government decides whether to maintain the current policy. If not, they decide which new policy should be adopted.

$g_{t}=\left\{\begin{array}{ll}g^{0} & \text { for } t \leq \tau, \\ g^{0} & \text { for } t>\tau \\ g^{n} & \text { for } t>\tau\end{array}\right.$ if the old policy is retained(i.e. no policy change),

where $g^{0}$ is the impact of the old policy; $g^{n}$ is the impact of the $n$-th new policy. The average profitability changes if a policy changes from $g^{0}$ to $g^{n}$. All policies are effective immediately; however, the value of each policy is unknown in the time interval of $[0, T]$. That is, the economic policy that impacts investor profitability is uncertain. Policy uncertainty can be denoted by $\sigma_{g}$, which is the variance of $g_{t}$.

In addition, the model introduces an incomplete information to describe the government's policy choices. The government faces a "political cost" (or benefit) associated with any changes of policy. For any $C^{n}>0, C^{n}>1$ indicates that the political cost is higher than the benefit. Only the government can observe the value of $C$ and decide policy according to it. Since $E[C]=1$, the government is expected to maximize the investor's utility, but it may deviate from this objective randomly as the political cost is uncertainty. ${ }^{1}$ The investors cannot directly observe $C$ but they know its distribution. Political uncertainty can be represented by the variance of political cost $\left(\sigma_{c}\right)$, which is complex, non-transparent and captures the difficulty faced by investors in predicting the outcome of a political decision.

Based on this, the model builds up a framework in a general equilibrium based on investor utility and government benefit maximization. Risk-averse investors will demand additional risk premiums under this uncertainty. However, the model potentially assumes that the policy itself is not aimed at

\footnotetext{
${ }^{1}$ The assumption that governments do not behave as fully benevolent social planners is widely accepted in the political economic literature (see Aleasina and Tabellini, 1990; Grossman and Helpman, 1994). We adopt a simple reduced-form approach to modeling departures from benevolence.
} 
the real estate market, but that the uncertainties arising from policy changes affect the real estate market. This setting may sometimes reflect the real impact of economic policy uncertainty on asset prices if these assets are not the main object of policy changes. However, considering that real estate has a tremendous impact on economic stability, policy changes may mainly aim at keeping house prices stable. If this is the case, the economic policy uncertainty could cause house prices to continue to rise steadily and reduce the volatility of real estate when it faces the possibility of huge fluctuations. To this end, we will further use empirical means to verify our conjecture.

\section{METHODOLOGY}

\subsection{Bootstrap full-sample Granger causality test}

The Granger-causality statistics assume that the underlying time series are stationary and that they may not have standard asymptotic distributions when the stationarity assumption does not hold. In this condition, there will be difficulties in the levels of estimation of VAR models (Sims et al., 1990; Toda and Phillips, 1993, 1994). Shukur and Mantalos (1997a) use Monte Carlo simulations to evaluate the power and size properties of the modified Wald test. However, the Wald test does not have the correct size in small and medium-size samples. Nevertheless, Shukur and Mantalos (1997b) indicate that critical values in power and size are improved significantly if the residualbased bootstrap (RB) method is used. Moreover, the excellent performance of the RB method over standard asymptotic tests, regardless of cointegration, has been confirmed in a number of studies involving Monte Carlo simulations (Mantalos and Shukur, 1998; Shukur and Mantalos, 2000; Mantalos, 2000; Hacker and Hatemi-J, 2006; Balcilar et al., 2010). In particular, Shukur and Mantalos (2000) prove that small sample corrected likelihood-ratio (LR) tests exhibit relatively better power and size properties. Their results indicate that in the absence of cointegration, all standard tests that do not use the RB method perform inadequately, particularly in small samples. Based on these findings, we resort to the RB-based modified-LR statistic to examine the Granger causality between economic policy uncertainty and house prices with controlling the interest rate of housing loans.

We use an equation in which the three variables $\operatorname{VAR}(p)$ process as follows, where $p$ is the optimal lag length that is determined by the Schwarz Information Criteria (SIC). We use this VAR model to demonstrate the RB based modified-LR causality test: 


$$
\mathbf{y}_{t}=\phi_{0}+\phi_{1} \mathbf{y}_{t-1}+\ldots+\phi_{p} \mathbf{y}_{t-p}+\boldsymbol{\varepsilon}_{t}, \quad t=1,2, \ldots, T,
$$

where $\boldsymbol{\varepsilon}_{t}=\left(\varepsilon_{E P U, t}, \varepsilon_{H P, t}, \varepsilon_{I R, t}\right)^{\prime}$ is a zero mean, independent, white noise process with nonsingular covariance matrix $\boldsymbol{\Sigma}$. We partition the variable $\mathbf{y}_{t}$ into three sub-vectors $\mathbf{y}_{t}=\left(E P U_{t}, H P_{t}, I R_{t}\right)^{\prime}$, where $E P U$ denotes the economic policy uncertainty, $H P$ denotes house prices and $I R$ denotes the interest rate of housing loans. Thus, the above equation can be written as the following:

$$
\left[\begin{array}{c}
E P U_{t} \\
H P_{t} \\
I R_{t}
\end{array}\right]=\left[\begin{array}{c}
\phi_{E P U, 0} \\
\phi_{H P, 0} \\
\phi_{I R, 0}
\end{array}\right]+\left[\begin{array}{ccc}
\phi_{E P U, E P U}(L) & \phi_{E P U, H P}(L) & \phi_{E P U, I R}(L) \\
\phi_{H P, E P U}(L) & \phi_{H P, H P}(L) & \phi_{H P, I R}(L) \\
\phi_{I R, E P U}(L) & \phi_{I R, H P}(L) & \phi_{I R, I R}(L)
\end{array}\right]\left[\begin{array}{c}
E P U_{t} \\
H P_{t} \\
I R_{t}
\end{array}\right]+\left[\begin{array}{c}
\varepsilon_{E P U, t} \\
\varepsilon_{H P, t} \\
\varepsilon_{I R, t}
\end{array}\right]
$$

where $\phi_{i, j}(L)=\sum_{k=1}^{p} \phi_{i j, k} L^{k}, L$ is the lag operator defined as $L^{k} x_{t}=x_{t-k}$.

Based on Equation (4), the null hypothesis that HP does not Granger-cause EPU is tested by imposing the restriction $\phi_{E P U, H P, k}=0$ for $k=1,2, \ldots, p$. Similarly, the null hypothesis that EPU does not Granger-cause HP is tested by imposing the restriction $\phi_{H P, E P U, k}=0$ for $k=1,2, \ldots, p$. As discussed, the full-sample causality tests in this study rely upon RB-based p-values and modified-LR statistics. If the first null hypothesis is rejected, then there is a significant Granger causality running from HP to EPU, which means that HP can predict movements in EPU significantly. Similarly, if the second null hypothesis is rejected, then there is a significant Granger causality running from EPU to HP, which means that EPU can predict movements in HP significantly.

\subsection{Parameter stability test}

To verify the validity of the results, the full-sample causality tests usually assume that parameters of the VAR model used do not have the structure changes. However, the structural changes of the underlying full-sample time series always exist in the VAR model that will cause results from the fullsample causality tests to be invalid, and hence, the causal links between the series would show instability (Balcilar and Ozdemir, 2013). Andrews (1993) and Ploberger (1994) developed the Sup-F, Mean-F and Exp-F tests to 
investigate short-term parameter stability. We apply the $\mathrm{L}_{\mathrm{c}}$ test (Nyblom, 1989; Hansen, 1992) for all parameters in the overall VAR system. These tests are calculated from the sequence of LR statistics, and they are used to check the stability of parameters to solve the problem of the alternative of a single structural break at an unknown time. Moreover, because these tests exhibit non-standard asymptotic distributions, critical values and $p$-values are proposed by means of the parametric bootstrap procedure (Andrews, 1993; Andrews and Ploberger, 1994). Specifically, the critical values and $p$ values are obtained using asymptotic distribution constructed by means of Monte Carlo simulations using 10,000 samples generated from a VAR model with constant parameters. In addition, the Sup-F, Mean-F and Exp-F are required for 15 percent trimming from both ends of the sample (Andrews, 1993). Therefore, we apply the $(0.15,0.85)$ fraction of the sample in these tests. With respect to the $\mathrm{L}_{c}$ tests, they are computed for equations and the VAR system separately.

\subsection{Sub-sample rolling-window Granger causality test}

To overcome the parameter non-constancy and to avoid pre-test bias, we apply the rolling-window bootstrap estimation (Balcilar et al., 2010). There are two important reasons for using the rolling estimation. First, the causal relationship between variables can change over time in the rolling-window method. Second, rolling estimation can observe instability across different sub-samples due to structural change, and the rolling-window estimation captures this process.

The rolling-window techniques rely on fixed-size sub-samples sequentially rolling from the beginning to the end of the full sample (Balcilar et al., 2010). In this premise, setting a fixed-size rolling window including $l$ observations, the full sample is converted to a sequence of $T-l$ subsamples, that is, $\tau-l+1, \tau-l, \ldots, T$ for $\tau=l, l+1, \ldots, T$. It can then apply the RB-based modified-LR causality test to each sub-sample, instead of estimating a single causality test for a full sample. Possible changes in the causal links between HP and EPU are intuitively identified by calculating the bootstrap p-values of observed LR-statistics rolling through $T-l$ subsamples. The impact of EPU on HP is defined as the average of the entire bootstrap estimates derived from the formula $N_{b}^{-1} \sum_{k=1}^{p} \hat{\phi}_{H P, E P U, k}^{\star}$ with $N_{b}$ representing the number of bootstrap repetitions; similarly, the impact of HP 
on EPU obtained from the formula $N_{b}^{-1} \sum_{k=1}^{p} \hat{\phi}_{E P U, H P, k}^{\star}$. Both $\hat{\phi}_{H P, E P U, k}^{\star}$ and $\hat{\phi}_{E P U, H P, k}^{\star}$ are bootstrap estimates from the VAR models in Equation (4). The 90-percent confidence intervals are also computed, for which the lower and upper limits equal the 5th and 95th quantiles of each of the $\hat{\phi}_{H P, E P U, k}^{\star}$ and $\hat{\phi}_{E P U, H P, k}^{\star}$, respectively (Balcilar et al., 2010).

There are two conflicting objectives in the rolling-window estimation: accuracy of the parameter estimates and the representativeness of the model over the sub-sample period. The window size affects the precision of estimations, and influences the number of observations. A large window size may improve the accuracy of estimates but may reduce the representativeness in the presence of heterogeneity. However, a small window size may improve the representativeness and reduce accuracy. Consequently, we must select a suitable window size to balance the trade-off between representativeness and accuracy. Pesaran and Timmerman (2005) demonstrate that the optimal window size depends on the persistence and size of the break by assessing the window size under structural change, which is according to square root mean square error. More importantly, based on Monte Carlo simulations, they propose that the minimum limit of window size is 20 when there are frequent breaks. Taking this and the two conflicting demands of the previous paragraph together, we choose a window size of 24 months (this excludes the observations required for lags and, hence, is the actual number of observations in the VAR). A large window size is needed to ensure the precision of parameter estimates, but a window size that is too large may increase the risk of including some of these multiple shifts in the window sample claims for a smaller window size. As for the issue of inaccurate estimates as a result of the selected small window size, this can be addressed by the bootstrap technique employed in the rolling estimation for better precision.

\section{DATA AND EMPIRICAL RESULTS}

The empirical part uses monthly data ranging from 2005M1 to 2018M12. Among them, data of HP is a new released housing price index by the Hypoport Group database. This index describes apartments and free-standing homes (new and existing), starting at 2005M1. The HP index has a base 
period of $2005 \mathrm{M} 8$ and a base value of 100 . This index is extracted for anonymous transactions on the EUROPACE-platform. It is sufficiently representative in Germany since roughly 10 percent of all real estate financing for private customers in Germany is executed using the EUROPACE-platform, which is the only independent marketplace in Germany. In this paper, we show the deflation of the HP index using the consumer price index (CPI) obtained from the International Monetary Fund (IMF) electronic database. The widely used EPU index of Germany proposed by Baker et al. (2016) is utilized to measure the uncertainty of German economic policies. This index includes uncertainties regarding tax, spending, monetary and regulatory policy by the government that was built on three components: the frequency of newspaper references to economic policies, the number of federal tax code provisions set to expire, and the extent of forecaster disagreement over future inflation and government purchases. We obtain this index from the Economic Policy Uncertainty Database. In addition, we hope to exclude as much as possible the impact of policy formulation on HP in order to examine whether EPU is mainly in uncertainty or in economic policy under such circumstances. Thus we also control the interest rate of housing loan (IR) in the VAR model since it clearly shows an opposite long-term trend with HP. The data of IR is obtained from the IMF electronic database. To further test the volatility spillover effect of EPU on the real estate market, we also calculate the conditional volatility (VOL) using the $\operatorname{GARCH}(1,1)$ model (generalized auto-regressive conditional heteroscedasticity model) with $t$-distribution.

Although not shown in the paper, the long-term house prices show a steady upward trend across the sample period. Especially after 2016, HP of Germany shows an abnormal trend of rapid growth. The main reason for the rise is that supply exceeds demand. Although the numbers of new houses are increasing in Germany, the rate of housing construction is far behind the rate of population growth. According to the Federal Association of German Housing and Real Estate Companies (GDW), Germany has built one million fewer houses since 2009. They believe that the reason for the increase in housing demand is that the German population has increased by 2.5 million since 2009, mainly due to the increase in the number of immigrants. In its outlook for the German housing market in 2017, Deutsche Bank said that in the five years from 2011 to 2016, Munich had completed 45,000 new housing units, which accommodated about 90,000 people, but the city's population increased by 200,000 in the same period. The capital, Berlin, has similar figures. In addition, data released by the Peel Institute in Hanover 
show that 100,000 so-called social housing units have disappeared from the market in the past ten years. Social housing has long been the stabilizer of the German housing market, and their disappearance means that many of the cheaper houses of the past are dominated by big companies and are marketoriented. ${ }^{2}$ We find that the volatility of housing returns in Germany has risen rapidly since 2013M6, and dropped sharply since 2016M7. During this period, there may be factors that the government used to regulate house prices. If so, the EPU should impact the German housing market mainly by "economic policy" but not "uncertainty". At the same time, changes in house prices may also be the reason for the frequent changes in government economic policies. Evidence from the trend of EPU shows that the periodic fluctuation of EPU seems to be more consistent with that of HR. Especially in the period from 2015M7 to 2017M11, both of them show greater fluctuations. Based on this, we speculate that in view of the important economic status of real estate, there may be a bilateral Granger causality between the real estate market and EPU. The real estate market can affect policy formulation to a large extent, and policy changes may be mainly aimed at stabilizing house prices (reducing house price fluctuations and ensuring its stable growth).

The above analysis also shows a very important feature of the time series: structural changes. For example, HR volatility fluctuates greatly after 2015, but is relatively stable before 2015. In addition, the EPU index fluctuates greatly in the late 2008 financial crisis and after 2016, while it is relatively stable in other periods. This structural change is a great challenge to the traditional method of full sample statistics. For example, it is doubtful whether the traditional unit root test (such as the ADF test) can really verify the stationarity of data (Enders and Lee, 2012a; Enders and Lee, 2012b; Enders and John, 2016). A lot of empirical studies have found that after considering structural changes, the unstable series based on traditional unit root tests (such as the augmented Dickey-Fuller test proposed by Dickey and Fuller, 1981) is actually stable (Su et al., 2011; Furuoka, 2014). However in spite of potential structural changes, we first estimated a full sample VAR model as a benchmark result. As discussed before, we use the RB-based modified-LR statistic to examine the Granger causality between EPU and HP (controlling for IR). The optimal lag lengths based on the Schwarz

\footnotetext{
${ }^{2}$ Voigtländer (2012) investigates the stability of the German housing market and proves its uniqueness in retaining flat price levels over the whole period and failing to respond to any of the macroeconomic shocks. He argues that the main reason for this stability can be found in real estate finance and in the existence of a sophisticated rental market.
} 
Information Criterion (SIC) of VAR models are both 2. The corresponding results are shown in Table 1.

There is no Granger causality from EPU and HP to IR at 5\% significance level, which suggests IR is an exogenous policy shock that is not determined by HP or EPU. That is, the change of IR is the active regulation behavior of the monetary authority of Germany which is not affected by house prices. Table 1 also shows that IR has a significant impact on HP and EPU, which suggests that interest rate policy is an important part of economic policy, and changes in interest rates can effectively cause changes in HP. This further proves that controlling the impact of IR is essential for the investigation of Granger causality between HP and EPU. We find a significant bilateral Granger causality between EPU and HP. This is in line with our previous speculation that HP as an important component of economic growth has a great impact on policy making, and EPU should also play a regulatory or risk spillover effect when the real estate market fluctuates enormously.

Table 1

Full-sample Granger causality test in Germany

\begin{tabular}{l|c|c|c}
\hline \multirow{2}{*}{ EPU } & EPU & HP & IR \\
\cline { 2 - 4 } & & $8.703^{* *}$ & $5.844^{*}$ \\
\hline \multirow{2}{*}{$\mathrm{HP}$} & $7.818^{* * *}$ & $(0.020)$ & $(0.070)$ \\
\cline { 2 - 4 } & $(0.000)$ & & 5.800 \\
\hline \multirow{2}{*}{$\mathrm{IR}$} & $7.597^{* * *}$ & $8.395^{* *}$ & \\
\cline { 2 - 4 } & $(0.010)$ & $(0.030)$ & \\
\hline
\end{tabular}

Notes: Columns (1) to (3) take EPU, HP and IR as dependent variables, respectively. $*, * *$ and $* * *$ denote significance at 10,5 and 1 percent levels, respectively. Causality tests are based on a VAR model, with the lag-length determined by the Schwarz Information Criteria (SIC). Residual-based bootstrap LR statistics, as suggested by Shukur and Mantalos (1997), are used to account for small-sample bias. Values in parentheses are the corresponding probabilities.

Source: author's calculations.

However, as discussed before, one question is still unclear, of why does EPU affect HP so significantly? Based on Pastor and Veronesi (2011), the risk spillover effect caused by uncertainty may be the one of the factors. This inference is mainly based on the investment attribute of real estate as an asset. However, as an important part of the real economy, the impact of EPU on the real estate market may not only come from uncertainty, but also from the targeted policies themselves. Generally, the above two forces should be 
opposite. Uncertainty may be detrimental to the real estate market, but targeted policies may tend to stabilize house prices. The full sample test does not help us to distinguish the strength of these two forces. Therefore, next we are going to implement a rolling-window Granger causality test for the investigation. So far we have speculated that there are structural changes in HP and EPU without statistical evidence. Thus, we test the stability of parameters in the VAR model before the rolling-window test. This is important for the next investigation, since if structural changes do not exist, there is no need to use the rolling-window strategy. Another reason for the test of parameter stability is that the full-sample VAR models are not always statistically reliable on assumptions of parameter constancy across the whole sample period (Zeileis et al., 2005). For the reasons above, we test the stability of parameters and verify that there are structural changes in the full-sample time series. As mentioned in the previous section, we use three statistics, including the Sup-F, Mean-F and Exp-F tests developed by Andrews (1993) and Andrews and Ploberger (1994) to investigate the temporal stability of parameters in the VAR models above. We also use the $\mathrm{L}_{\mathrm{c}}$ test of Nyblom (1989) and Hansen (1992) to test for all parameters in the overall VAR system.

The results of the stability of parameters are reported in Table 2 (for the short run) and Table 3 (for the long run). Although the null hypothesis of Sup-F test, Mean-F test and Exp-F test is constant, their alternative hypotheses are different (Andrew and Ploberger, 1994). Among these three statistics, the Sup-F tests whether a shift in regime occurs, while the Mean-F and Exp-F test the gradual stability of the model over time and assume that the parameters follow the martingale process. The Sup-F statistic in Table 2 suggests that shifts in all the equations and the overall VAR(3) system exist at the 5-percent level. The Mean-F and Exp-F suggest that all the equations may evolve gradually over time. In most cases the $\mathrm{L}_{c}$ statistics test against the alternative that the parameters follow the random walk process proposed by Gardner (1969), indicative of parameter non-constancy in the $\operatorname{VAR}(3)$ model estimated. The long-term tests in Table 3 show similar results suggesting that in the parameters in the $\operatorname{VAR}(3)$ model exist kinds of structural changes (shifts or breaks). Overall, due to the instability of short and long-term parameters, the results of the full sample causality test are not reliable. To take structural changes into account, we employ rolling-window estimation to test the causal relationship between HP and EPU. Different from the full-sample causality test, this approach is superior in testing the causal relationship between two variables for the reason of time-varying across different sub-samples. 
Table 2

Short-term parameter stability tests in Germany

\begin{tabular}{c|c|c|c|c}
\hline & EPU Equation & HP Equation & IR Equation & VAR(2) System \\
\hline \multirow{2}{*}{ Sup-F } & $37.384^{* * *}$ & $70.323^{* * *}$ & $117.884^{* * *}$ & $48.781^{* *}$ \\
\cline { 2 - 5 } & $(0.000)$ & $(0.000)$ & $(0.000)$ & $(0.014)$ \\
\hline \multirow{2}{*}{ Mean-F } & $12.866^{* *}$ & $17.745^{* * *}$ & $20.283^{* * *}$ & $30.013^{* *}$ \\
\cline { 2 - 5 } & $(0.025)$ & $(0.001)$ & $(0.000)$ & $(0.029)$ \\
\hline \multirow{2}{*}{ Exp-F } & $14.597^{* * *}$ & $30.382^{* * *}$ & $54.214^{* * *}$ & $20.119^{* *}$ \\
\cline { 2 - 5 } & $(0.000)$ & $(0.000)$ & $(0.000)$ & $(0.017)$ \\
\hline \multirow{2}{*}{$\mathrm{L}_{b}^{\mathrm{c}}$} & 1.233 & $2.568^{* * *}$ & $2.010^{* *}$ & $5.810^{* * *}$ \\
\cline { 2 - 5 } & $(0.326)$ & $(0.005)$ & $(0.034)$ & $(0.005)$ \\
\hline
\end{tabular}

Notes: Columns (1) to (3) test the parameter stability for EPU, HP and IR equations, respectively; column (4) tests the parameter stability of the overall VAR system. ** and *** denote significance at 5 and 1 percent levels, respectively. Values in parentheses are the corresponding probabilities.

Source: author's calculations.

Table 3

Long-term parameter stability tests in Germany

\begin{tabular}{c|c|c|c|c}
\hline & Sup-F & Mean-F & Exp-F & $\mathrm{L}_{b}^{\mathrm{c}}$ \\
\hline Statistic & $268.220^{* * *}$ & $146.155^{* * *}$ & 130.675 & $13.208^{* * *}$ \\
\hline$p$-values & $(0.000)$ & $(0.000)$ & $(1.000)$ & $(0.005)$ \\
\hline
\end{tabular}

Notes: *** denote significance at 5 and 1 percent levels, respectively. Values in parentheses are the corresponding probabilities.

Source: author's calculations.

In the sub-sample causality rolling-window test we use the RB-based modified-LR causality tests to check the Granger causal relationship between HP and EPU and controlling for IR. The null hypothesis of the tests is that EPU does not Granger-cause HP and vice versa. The bootstrap $p$ values of LR-statistics can be estimated from the VAR models in Equation (4) by using the rolling sub-sample data including 24-month observations. ${ }^{3}$

\footnotetext{
${ }^{3}$ Though an interpretation for the selection of 24-month window size has been mentioned earlier, we still implemented different bootstrap rolling-window causality tests using 20-, 30- and 36month window size and estimated the magnitude of the effect of EPU on HP and that of HP on EPU. The results proved very similar to those from the causality test based on the 24-month window size, which further indicates that the results based on the 24-month window size are robust. The details of these results are available upon request from the authors.
} 
In addition, the results are presented in tests of causal relationship between variables in Germany by the approach of RB-based modified-LR causality tests. ${ }^{4}$ Figure 1 shows the rolling-window Granger causality between EPU and HP. Figures $1 \mathrm{a}$ and $1 \mathrm{~b}$ are the time-varying p-values of the RB based modified-LR statistics, we set the significance level of 10 percent (the red line) as the division of whether the Granger causality exists. Figures 1c and $1 \mathrm{~d}$ plot time-varying coefficients based on the bootstrap methods, where the green line is the maximum coefficient in 1000 bootstraps, the blue line is the average value and the red line is the minimum value. A significant relationship exists between grey-area representatives.

In general, the results from the sub-sample rolling window are consistent with those of the full-sample test, and further exhibit more accurate results (structural changes) across the full-sample time period. EPU and HP show significant Granger causality in most periods after controlling IR. The overall results are consistent with the full-sample results, indicating that EPU and HP can interact in most cases. However, the results from the rollingwindow test show a clear time-varying nature of their correlation in more detail. The significant effect of HP on EPU seems to be periodically distributed throughout the full-sample period, indicating that the periodic fluctuation of HP will lead to the change of EPU. This confirms the important position of HP in the national economy. The influence coefficient of HP on EPU does not show too strong regularity. We speculate that the reason is that the goal of policy changes is to stabilize HP. That is to say, the government neither wants HP to rise too fast, nor does it want HP to fall. The goal of policy making is to maintain HP growth at a reasonable level. When HP rises rapidly, there may be frequent policy changes to reduce its growth rate. In this case, the impact of HP on EPU is positive. On the contrary, when HP falls, policies will change frequently to stimulate house prices to rise, which forms a negative impact of HP on EPU. The impact of EPU on HP is mainly concentrated after the 2008 financial crisis and after 2015. EPU has a positive effect on HP in most periods with significant effects. Considering the long-term trend of it rising, especially the unprecedented growth rate of HP in Germany after 2015, we believe that frequent policy changes are aimed at reducing HP's growth rate to maintain its stability. The government will not impose excessively strong policy measures to make HP fall because it is not conducive to economic growth.

\footnotetext{
${ }^{4}$ We also tried the Wald-based test and the corresponding result is very similar to the result we reported in this paper.
} 
Therefore, HP will continue to rise under frequent policy changes. Figure 1c proves the above speculation that the impact on HP is positive for most of the time when EPU had a significant impact. We also find that EPU sometimes had a negative impact on HP in some relatively short time intervals (2007M11-2008M10; 2015M5-2015M12; 2018M7-2018M12). We think the reasons may lie in two aspects. Firstly, excessive policy regulation and control results in a temporary decline in house prices; secondly, the uncertainty of policy changes has produced a volatility spillover effect, which exacerbates the fluctuation of house prices and makes them fall temporarily.

The above analysis seems to indicate that the impact of economic policies themselves is more important than the volatility spillover effect caused by uncertainty in the impact of EPU on HP. If that is the case, then the model provided by Pastor and Veronesi $(2010,2013)$ is not used correctly in Germany's real estate market. The increase of EPU may be to maintain the stability of house prices, rather than to enhance its volatility through the volatility spillover effect. In order to test this speculation more directly, we examined the correlation between house price volatility (VOL) and EPU in Figure 2. We expect that when VOL increases, policies will change frequently and VOL will decrease, that is, VOL will have a positive impact on EPU. In addition, we expect EPU to increase in order to reduce VOL, thus forming the negative impact of EPU on VOL. Figure 2 clearly proves our speculation. Figures $2 a$ and $2 b$ show tested p-values of the LR statistics; Figures $2 \mathrm{c}$ and $2 \mathrm{~d}$ show the corresponding coefficients based on 1000 bootstraps. Firstly, the time intervals of EPU and VOL are much less than that of Figure 1, which indicates that the effects of EPU and VOL may exist only when VOL is higher. Overall, the significant correlation between EPU and VOL is mainly in 2010-2013 and beyond 2015. Among those, German HP has been relatively stable before 2011 without an obvious upward trend. However, after 2011 German HP begins to show a relatively obvious upward trend, which may alert policymakers, thus triggering policy changes to make EPU and VOL more relevant. In addition, after 2015 Germany's HP growth rate further accelerated. Although this may be due to market factors such as increasing immigration and the shortage of housing supply and demand, this phenomenon has also led policymakers to pay more attention to the real estate market. We noticed a distinct feature from Figures $2 \mathrm{c}$ and $2 \mathrm{~d}$ that for most periods with significant correlation, EPU almost always has negative impacts on VOL, while VOL always has positive impacts on EPU. This result is very consistent with our previous speculation that the impact of 

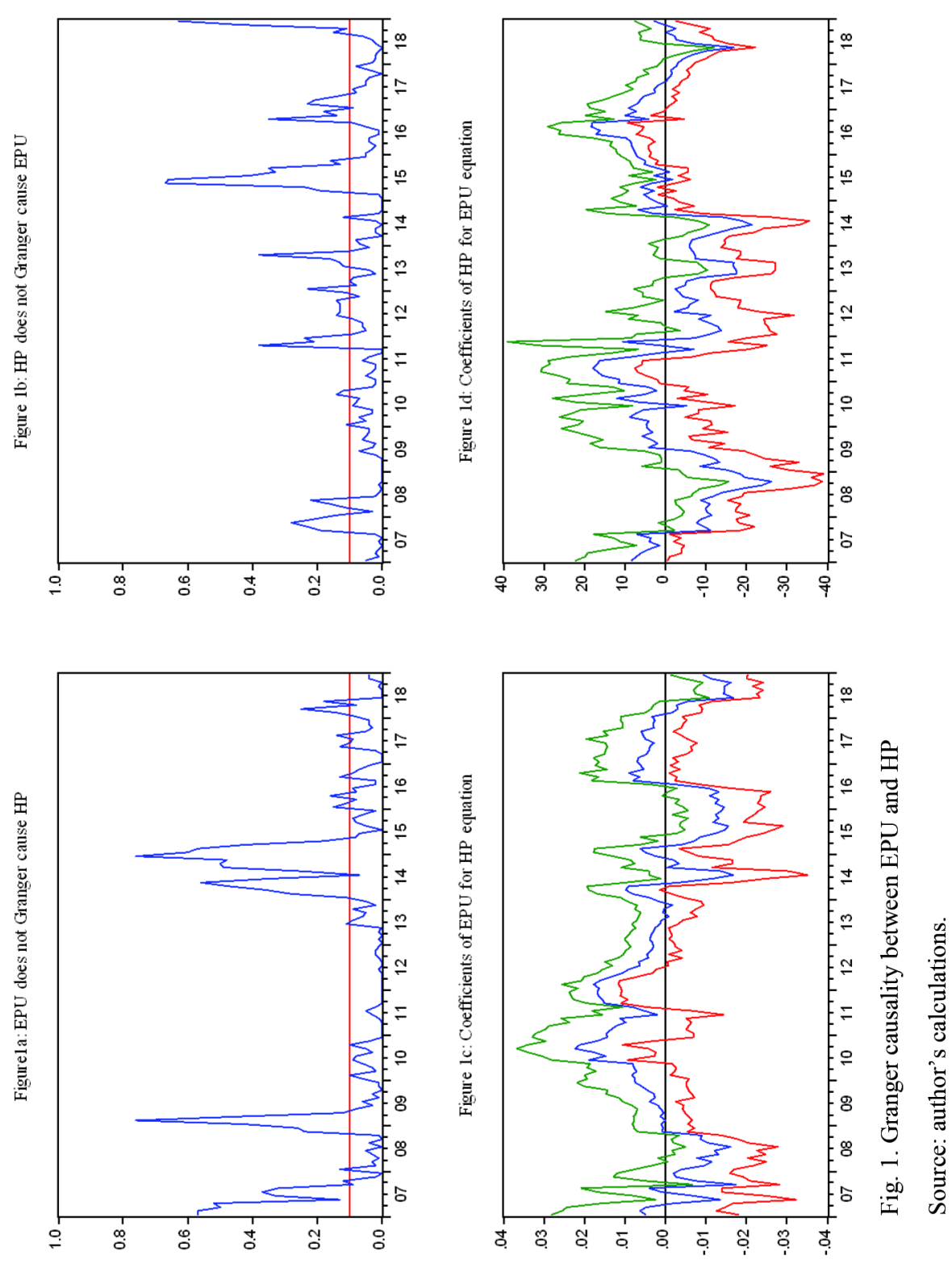

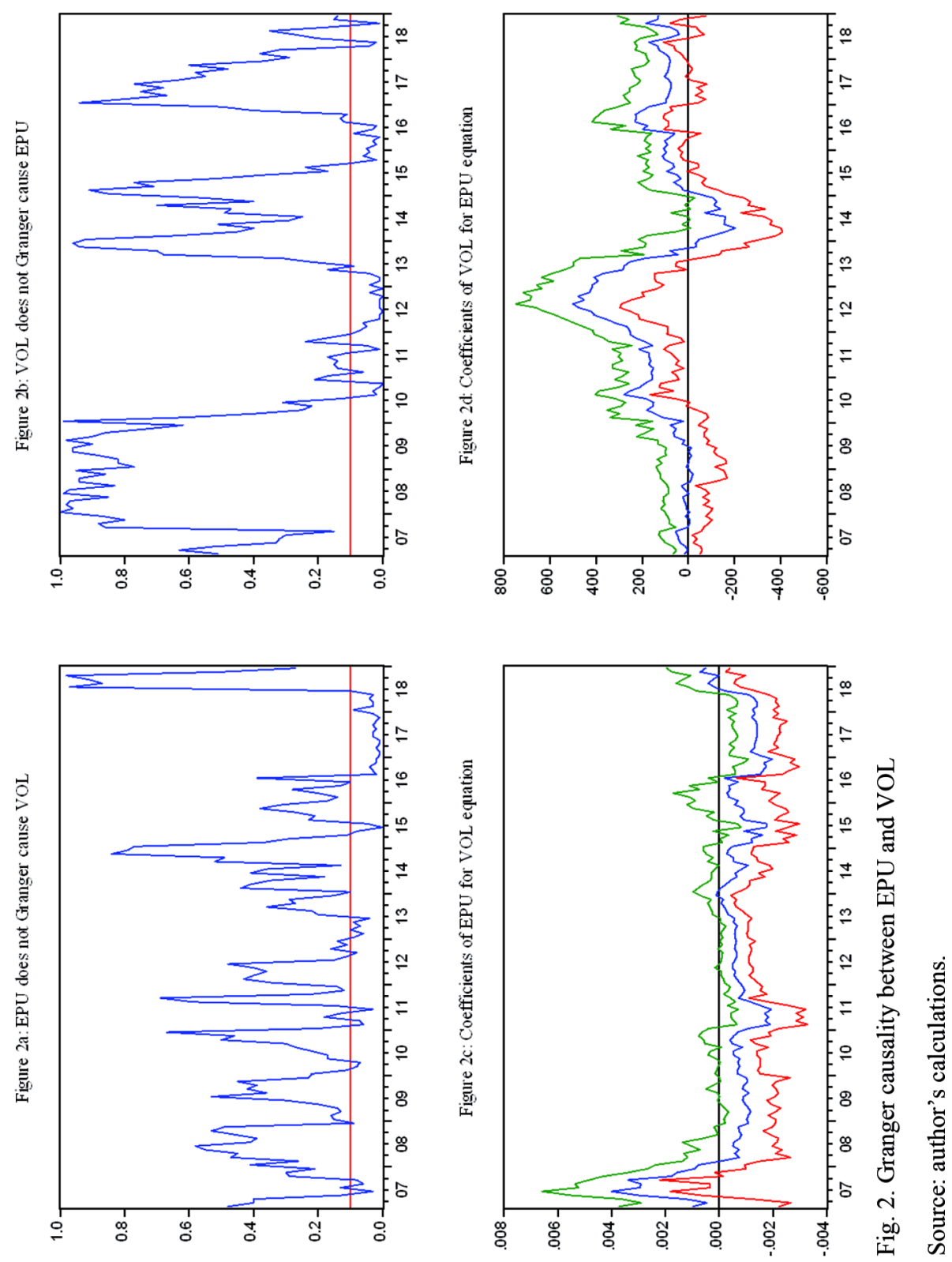
frequent policy changes lies mainly in the policy itself rather than the increase of uncertainty brought about by policy changes. When policy changes are aimed at stabilizing the real estate market, the impact of uncertainty becomes less important, and this is the main reason why our results do not conform to Pastor and Veronesi $(2010,2013)$.

\section{CONCLUSIONS}

Previous literature usually focused on the impact of economic policy uncertainty on economic variables. In this paper, we show evidence that it is one-sided to consider only the effect of uncertainty. In particular, when the variables studied belong to the pillar industries of the national economy, the impact of "economic policy" may be much higher than that of "uncertainty". Taking Germany's housing market as the example, we test the time-varying relationship between house prices and the uncertainty of economic policy by considering structural changes and controlling the interest rate of housing loans. We mainly use a rolling-window based Granger causality test for this investigation. Our results show that the Granger causality between prices of housing and economic policy uncertainty is time-varying but it seems to be bilateral and exists in most sample periods. The fact the economic policy uncertainty would increase house prices raises questions regarding Pastor and Veronesi (2010, 2013), who mainly focus on the risk premium of policy uncertainty on asset prices. We further examine the impact of economic policy uncertainty on the volatility of housing returns calculated using a $\operatorname{GARCH}(1,1)$ model. The results further provide evidence that the volatility spillover effect is not the main mechanism for economic policy uncertainty affecting the housing market. The correlation between economic policy uncertainty and volatility is more like unilateral Granger causality, which mainly occurs in periods of high volatility. In addition, economic policy uncertainty has a stable inhibitory effect on housing return volatility, while housing return volatility can enhance economic policy uncertainty. The results suggest that the housing market itself is enough to cause economic policy changes and frequent economic policy changes seem to be aimed at reducing housing return volatility.

Our results do not support the model of Pastor and Veronesi $(2010,2013)$ since it hardly shows any evidence that the volatility spillover effect of economic policy uncertainty has led to the rise of housing market volatility. We provide a new perspective to examine the impact of economic policy uncertainty that also makes it different from other kinds of uncertainty. 
Behind the uncertainty of economic policy, there may be a clear policy direction which may have a greater impact on macroeconomic variables than uncertainty. In addition, macroeconomic policy objectives may change in different periods, and the statistical means based on the whole sample are not enough to examine such changes, which also makes it difficult to reveal the regularity of the impact of economic policy uncertainty.

\section{REFERENCES}

Aizenman, J., Marion, N. P., Policy uncertainty, persistence and growth, "Review of International Economics", 1(2), pp. 145-163, 1993.

Alesina, A., Tabellini, G., A positive theory of fiscal deficits and government debt, "Review of Economic Studies", 57, pp. 403-414, 1990.

Andrews, D. W. K., Tests for parameter instability and structural change with unknown change point, "Econometrica", 61, pp. 821-856, 1993.

Andrews, D. W. K., Ploberger, W., Optimal tests when a nuisance parameter is present only under the alternative, "Econometrica", 62, pp. 1383-1414, 1994.

Aoki, K., Proudman, J., Vlieghe, G., House prices, consumption, and monetary policy: A financial accelerator approach, "Journal of Financial Intermediation", 13(4), pp. 414-435, 2004.

Aye, G. C., Balcilar, M., Gupta, R., Jooste, C., Miller, S. M., Ozdemir, Z. A., Fiscal policy shocks and the dynamics of asset prices: the South African experience, "Public Finance Review", 42(4), pp. 511-531, 2012.

Balcilar, M., Ozdemir, Z. A., Arslanturk, Y., Economic growth and energy consumption causal nexus viewed through a bootstrap rolling window, "Energy Economics", 32(6), pp. 1398$-1410,2010$.

Balcilar, M., Ozdemir, Z. A., The export-output growth nexus in Japan: A bootstrap rollingwindow approach, "Empirical Economics", 44, pp. 639-660, 2013.

Brogaard, J., Detzel, A., The Asset-Pricing Implications of Government Economic Policy Uncertainty, "Management Science", 61(1), pp. 3-18, 2015.

Calza, A., Monacelli, T., Stracca, L., Housing finance and monetary policy, "Journal of the European Economic Association”, 11, pp. 101-122, 2013.

Demyanyk, Y., Van Hemert, O., Understanding the subprime mortgage crisis, "Review of Financial Studies", 24(6), pp. 1848-1880, 2011.

Dickey, D. A., Fuller, W. A., Likelihood ratio statistics for autoregressive time series with a unit root, "Econometrica: Journal of the Econometric Society", pp. 1057-1072, 1981.

Dufour, J. M., Dummy variables and predictive tests for structural change, "Economics Letters", 6(3), pp. 241-247, 1980.

Enders, W., Jones, P., Grain prices, oil prices, and multiple smooth breaks in a VAR, "Studies in Nonlinear Dynamics \& Econometrics”, 20(4), pp. 399-419, 2016.

El-Montasser, G., Ajmi, A. N., Chang, T., Simo-Kengne, B. D., Andre, C., Gupta, R., Crosscountry evidence on the causal relationship between policy uncertainty and house prices. University of Pretoria, Department of Economics, 2013. 
Enders, W., Lee, J., A unit root test using a Fourier series to approximate smooth breaks, "Oxford Bulletin of Economics and Statistics", 74(4), pp. 574-599, 2012a.

Enders, W., Lee, J., The flexible Fourier form and Dickey-Fuller type unit root tests, "Economics Letters", 117(1), pp. 196-199, 2012 b.

Feng, Y., Political freedom, political instability, and policy uncertainty: A study of political institutions and private investment in developing countries, "International Studies Quarterly", 45(2), pp. 271-294, 2001.

Furuoka, F., Are unemployment rates stationary in Asia-Pacific countries? New findings from the Fourier ADF test, "Economic research-Ekonomska istraživanja", 27(1), pp. 34-45, 2014.

Granger, C. W. J., Can we improve the perceived quality of economic forecasts?, "Journal of Applied Econometrics", 11, pp. 455-73, 1996

Grossman, G. M., Helpman, E., Protection for sale, “American Economic Review”, 84, pp. 833$-850,1994$.

Hacker, R. S., Hatemi-J, A., Tests for causality between integrated variables based on asymptotic and bootstrap distributions: Theory and application, "Applied Economics", 38, pp. 1489$-1500,2006$.

Hansen, B. E., Tests for parameter instability in regressions with I(1) processes, "Journal of Business and Economic Statistics”, 10, pp. 321-336, 1992.

Karanikolos, M., Mladovsky, P., Cylus, J., Thomson, S., Basy, S., Stuckler, D., Mackenbach, J., Mckee, M., Financial crisis, austerity, and health in Europe. "The Lancet", 381(9874), pp. 1323-1331, 2013.

Kwiatkowski, D., Phillips, P. C., Schmidt, P., Shin, Y., Testing the null hypothesis of stationarity against the alternative of a unit root: How sure are we that economic time series have a unit root?, "Journal of Econometrics", 54(1), pp. 159-178, 1992.

Lee, J., Strazicich, M. C., Minimum LM unit root test with one structural break. Manuscript, pp. 1-16. Department of Economics, Appalachian State University, 2004.

Mantalos, P., Shukur, G., Size and power of the error correction model cointegration test: A bootstrap approach, "Oxford Bulletin of Economics and Statistics", 60, pp. 249-255, 1998.

Mantalos, P., A graphical investigation of the size and power of the granger-causality tests in integrated-cointegrated VAR systems, "Studies in Non-Linear Dynamics and Econometrics", 4, pp. 17-33, 2000.

Nyblom, J., Testing for the constancy of parameters over time, "Journal of the American Statistical Association”, 84, pp. 223-230, 1989.

Pesaran, M. H., Timmermann, A., Small sample properties of forecasts from autoregressive models under structural breaks, "Journal of Econometrics", 129, pp. 183-217, 2005.

Phillips, P. C. B., Hansen, B. E., Statistical inference in instrumental variables regression with I (1) processes, "Review of Economics Studies", 57, pp. 99-125, 1990.

Pastor, L, Veronesi, P., Political uncertainty and risk premia, "Journal of Financial Economics", 110(3), pp. 520-545, 2013.

Pastor, L, Veronesi, P., Uncertainty about government policy and stock prices, "The Journal of Finance", 67(4), pp. 1219-1264, 2010. 
Perron, P., The great crash, the oil price shock and the unit root hypothesis, "Econometrica", 57(6), pp. 1361-1401, 1989.

Sims, C. A., Stock, J. H., Watson, M. W., Inference in linear time series with some unit roots, "Econometrica", 58 (1), pp. 113-144, 1990.

Shukur, G., Mantalos, P., Size and power of the RESET test as applied to systems of equations: a bootstrap approach. Department of Statistics, University of Lund, Sweden, 1997a.

Shukur, G., Mantalos, P., Tests for Granger causality in integrated-cointegrated VAR systems. Working paper. Department of Statistics, University of Lund, Sweden, $1997 \mathrm{~b}$.

Shukur, G., Mantalos, P., A simple investigation of the Granger-causality test in integratedcointegrated VAR Systems, "Journal of Applied Statistics", 27, pp. 1021-1031, 2000.

$\mathrm{Su}, \mathrm{C}$. W., Tsangyao, C., Chang, H. L., Purchasing power parity for fifteen Latin American countries: Stationary test with a Fourier function, "International Review of Economics \& Finance", 20(4), pp. 839-845, 2011.

Sum, V., Brown, K., Real estate sector response to economic policy uncertainty shocks, "International Research of Journal of Applied Finance", 3(12), pp. 1739-1747, 2012.

Toda, H. Y., Phillips, P. C. B., Vector autoregressions and causality, "Econometrica", 61, pp. 1367-1393, 1993.

Toda, H. Y., Phillips, P. C. B., Vector autoregression and causality: A theoretical overview and simulation study, "Econometric Reviews", 13, pp. 259-285, 1994.

Toda, H. Y., Yamamoto, T., Statistical inference in vector autoregressions with possibly integrated processes, "Journal of Econometrics", 66, pp. 225-250, 1995.

Van der Heijden, H., Dol, K., Oxley, M., Western European housing systems and the impact of the international financial crisis, "Journal of Housing and the Built Environment", 26(3), pp. 295-313, 2011.

Voigtländer, M., Why is the German homeownership rate so low?, "Housing Studies", 24(3), pp. 355-372, 2009.

Voigtländer, M., The stability of the German housing market, "Journal of Housing and the Built Environment", 29(4), pp. 583-594, 2014.

Zeileis, A, Leisch F., Hornik, K., Kleiber, C., Monitoring structural change in dynamic econometric models, "Journal of Applied Econometrics", 20, pp. 99-121, 2005.

Received: January 2016 